\title{
O TRABALHO DO AGENTE COMUNITÁRIO DE SAÚDE E AS DIFERENÇAS SOCIAIS NO TERRITÓRIO
}

\section{THE WORK OFTHE COMMUNITY HEALTH AGENT AND SOCIAL DIFFERENCES IN THE TERRITORY}

\author{
Cintya Cristine Martins da Veiga Faria ${ }^{1}$ iD (0000-0001-8344-9695), Carlos Henrique Assunção Paiva ${ }^{2}$ \\ (iD) $(0000-0002-7478-9628)$
}

\begin{abstract}
${ }^{1}$ Universidade Estácio de Sá, Programa de Pós-Graduação em Saúde da Família, Rio de Janeiro, RJ, Brasil.<cintyavfaria@gmail.com>

${ }^{2}$ Fundação Oswaldo Cruz, Casa de Oswaldo Cruz, Programa de Pós-graduação em História das Ciências e da Saúde, Rio de Janeiro, RJ, Brasil.
\end{abstract}

Resumo Neste artigo, discutem-se as diferenciações sociais apresentadas como desafios aos agentes comunitários de saúde no seu trabalho cotidiano. O estudo consistiu em analisar as configurações sociais construídas no território adscrito, com base na ação dos agentes. Destacam-se as ferramentas analíticas que permitem compreender os diferentes padrões de estratificação social entre grupos pertencentes a um mesmo ambiente socioeconômico. $\mathrm{O}$ método de pesquisa adotado baseou-se na abordagem qualitativa por meio de dez entrevistas semiestruturadas e acompanhamento em uma clínica da família do município do Rio de Janeiro em 2016 e 2017, valendo-se de técnicas socioetnográficas. Os resultados apontam para a existência de dificuldades que impedem a adesão da população adscrita aos serviços ofertados pela clínica da família, assim como para a identificação de grupos com diferenças de poder e prestígio. Reitera-se a questão sobre como as equipes de saúde lidam com configurações sociais específicas. Conclui-se que as relações estabelecidas no espaço que circunscreve as unidades de saúde da família necessitam ser constantemente monitoradas, para identificar possíveis diferenças na adesão decorrentes das configurações sociais específicas da população adscrita aos serviços de saúde.

Palavras-chave agentes comunitários de saúde; trabalho; adesão; configurações sociais específicas; território de saúde.
Abstract The article discusses the social differentiations presented as challenges to the community health agents in their daily work. The study consisted of analyzing the social configurations built in the assigned territory, based on the agents' action. We highlight the analytical tools that allow us to understand the different patterns of social stratification between groups belonging to the same socioeconomic environment. The research method adopted was based on the qualitative approach through ten semi-structured interviews and follow-up with a family clinic in Rio de Janeiro, in 2016 and 2017 using socio-ethnographic techniques. The results point to the existence of difficulties that prevent the adherence of the population to the services offered by the family clinic, as well as the identification of groups with differences in power and prestige. The question is reiterated about how health teams deal with specific social configurations. It is concluded that the relationships established in the space which circumscribes family health units need to be constantly monitored to identify possible differences in adherence resulting from the specific social configurations of the population enrolled in health services.

Keywords community health agents; work; accession; specific social settings; territory of health. 


\section{Introdução}

O homem não pode ser compreendido fora de suas relações com o mundo, de vez que é um 'ser situado', um ser do trabalho e da transformação do mundo. (...) nestas relações com o mundo, através de sua ação sobre ele, o homem se encontra marcado pelos resultados de sua própria ação. Atuando, transforma, cria uma realidade que, por sua vez, envolvendo-o, condiciona sua forma de atuar. Não há, portanto, como dicotomizar o homem do mundo, pois que não existe um sem o outro (Freire, 1979, p. 28).

O Programa de Agentes Comunitários de Saúde (PACS), oficialmente implantado pelo Ministério da Saúde em 1991, tinha como iniciativa buscar alternativas para melhoria das condições de saúde das comunidades. Consistia em uma nova categoria de trabalhadores, formada pela e para a própria comunidade, atuando e fazendo parte da saúde prestada nas localidades (Brasil, 2017). Baseado o experimento bem-sucedido do PACS, a Estratégia Saúde da Família (ESF), nos anos seguintes, foi se firmando como uma trama de fortalecimento do Sistema Único de Saúde (SUS).

De acordo com Viana e Dal Poz (2005), até recentemente o entendimento do Ministério da Saúde sobre os agentes é de que estes poderiam se converter em atores fundamentais para a organização do serviço básico de saúde no município e, em termos gerais, em personagens relevantes em um desejado processo de fortalecimento do SUS.

A mais recente Política Nacional de Atenção Básica (Brasil, 2017), contudo, ao promover importantes mudanças na área, produziu controvérsias entre os trabalhadores e estudiosos, que passaram desde então a sinalizar para a perspectiva de redução do quantitativo dos ACSs nas equipes de saúde e para a ausência real de prioridade da ESF. Em que pesem tais tensões e críticas, duas questões já apontadas por Viana e Dal Poz (2005) ainda se revelam expressivas no processo de organização das atividades dos agentes: a escolha do ACS realizada por meio de processo seletivo, avaliação, capacitação e assim por diante; e as conjunturas institucionais da gestão da saúde no âmbito local. Tais conjunturas englobam aspectos como: o grau de participação dos usuários, a formação dos conselhos de saúde, o grau de autonomia da gestão financeira, a força de trabalho disponível e a capacidade instalada disponível, entre outros.

Nesse sentido, o estudo de Viana e Dal Poz (2005) pode ainda sugerir que os ACSs se apresentem como um braço auxiliar na implementação do SUS e na organização dos sistemas locais de saúde. Entretanto, na perspectiva de fortalecimento do SUS, Merhy e Franco (2005), ao avaliarem as necessidades relacionadas à saúde dos usuários individuais e coletivos como objeto central no âmbito da saúde, não deixaram de visualizar algumas dificuldades por parte dos ACSs para o exercício do seu trabalho cotidiano. 
Seabra, Carvalho e Foster (2008), ao estudarem o ACS na visão da equipe mínima, reconhecem que ele tem uma identidade comunitária e realiza tarefas que não se restringem apenas ao campo da saúde. Assim, a convivência do ACS com a realidade e com as práticas de saúde do bairro em que mora e trabalha faz com que ora seja visto como membro da equipe de saúde, ora como membro da comunidade assistida.

Na leitura de Pereira e Barcellos (2006), contudo, as relações entre os agentes de saúde e as comunidades estão longe de se mostrarem pacíficas e não são necessariamente harmoniosas. Naquilo que envolve a relação do ACS com a comunidade do qual é parte, um exemplo dessa tensão se dá, de acordo com os autores, justamente na orientação da política na adscrição de clientela, cujo principal resultado é a inclusão de parcelas da população e exclusão de outras. O ACS, também como referem Queirós e Lima (2012), em seu contato direto com a clientela não deixa de sentir o descontentamento por parte dos excluídos.

Ao realizar sua intercomunicação com o território, o ACS é recebido, portanto, também como representante do governo na comunidade. Sua atuação surge tanto como um sujeito solidário quanto como um facilitador de cidadania. Quando os papéis se invertem, ou seja, quando o ACS passa a representar a comunidade em seu serviço, os conflitos surgem, já que ele emerge como um mediador de problemas e soluções, mas também é percebido como alguém que potencializa as reivindicações da população.

Tal questão, segundo o estudo realizado, se dá pelo fato de os usuários dos serviços de saúde não assimilarem o objetivo do trabalho, assim como pela forma como se delineiam as propostas que engendram as ações de promoção e de prevenção da má saúde. Sugere-se que essa incompreensão possa estar associada à resistência dos usuários às novas propostas, tanto quanto à falta de tempo em receber os ACSs no domicílio (Queirós e Lima, 2012).

Territórios caracterizados por alto risco social e sanitário, marcados pela violência, também compõem o espaço social, definindo os comportamentos, e se apresentam inseridos em uma perspectiva social orientada por diferentes arranjos. É nesse ambiente que figura a importância primordial de transformar a precária interação nas equipes e despreparo para lidar com a dimensão subjetiva nas práticas de atenção. Com esse entendimento, referimos a necessidade de existência de estudos que contemplem esse conteúdo, que sejam desenvolvidos para impulsionar a busca de estratégias possíveis de consolidação dos princípios preconizados pelo SUS, especialmente no que se refere aos pontos referentes à universalização, integralidade e equidade.

Nesse contexto, o presente artigo é fruto de reflexões produzidas com base na análise dos resultados de uma pesquisa realizada em determinado território adscrito da ESF da Clínica da Família Epitácio Soares Reis, localizada na área programática 3.3, zona norte, no bairro da Pavuna, que possui uma das maiores populações dentre os bairros do município do Rio de Janeiro. 
O objetivo consistiu em analisar as configurações sociais construídas no território adscrito com base na ação dos ACSs, assim como em seus relatos sobre os moradores dos condomínios e vilas que, por viverem no território há mais tempo, consideravam-se superiores, tanto socialmente quanto no aspecto de antiguidade no território, e acreditavam que os moradores do entorno, mesmo pertencentes ao território de abrangência, não mereciam ter o mesmo direito de acesso aos serviços ofertados pela unidade de saúde.

Nessa linha de abordagem, Elias e Scotson (2000) disponibilizam as ferramentas analíticas que permitem compreender os diferentes padrões de estratificação social entre grupos pertencentes a um mesmo ambiente socioeconômico, onde justamente se dá o 'trabalho vivo' do ACS.

O artigo inicia-se apresentando a abordagem teórica do problema, assim como os procedimentos metodológicos da pesquisa. Na sequência, são apresentados e discutidos os conceitos desenvolvidos com base na literatura abordada, separando-os em tópicos, cada um referente a um determinado aspecto evidenciado pela pesquisa. São abordados o conceito de pluralidade eliasiano, a caracterização do mapa falante e os obstáculos enfrentados pelo ACS na prática com a comunidade. A relação entre o sistema de cuidados de saúde e a conformação social de um território evidencia, assim, os novos desafios na área urbana que dificultam a adesão da população adscrita. No final, são relacionadas algumas questões com base nos achados da pesquisa.

\section{O conceito de pluralidade eliasiano tendo o ACS como exemplo dessa relação plural}

Na obra Os estabelecidos e os outsiders, Elias e Scotson (2000) discutem as relações estabelecidas em Winston Parva, nome fictício de uma pequena comunidade na periferia urbana de Londres, constituída por um grupo que pensava a si mesmo e se autorrepresentava como humanamente superior em relação aos demais, sendo estes estigmatizados como pessoas de menor valor.

O cenário analisado pelos autores não apresentava significativas discrepâncias socioeconômicas entre os grupos que fundamentassem tal exclusão: padrões habitacionais, nacionalidade, ascendência étnica, assim como ao seu tipo de ocupação, renda ou nível educacional. A única diferença identificada era a composição de um grupo de antigos residentes estabelecidos na região há algumas gerações; e outro, bastante difuso, composto por recém-chegados. Além de sinalizarem para preconceitos sociais e processos um tanto perversos de exclusão social, Elias e Scotson (2000) identificam a construção de padrões de coesão social e construção de autoimagem como fatores estruturantes da vida social.

Nesse sentido, observou-se que tanto a exclusão quanto a estigmatização dos outsiders pelo grupo mais antigo, os estabelecidos, eram recursos favoráveis para que preservassem sua identidade e ratificassem sua superioridade, ao mesmo tempo que mantinham os outros apartados. 
Os autores, ao tratarem da problemática das relações entre os indivíduos em uma comunidade, foram capazes de identificar e elucidar as relações de poder, dependência e exclusão existentes em uma sociedade específica, bem como visualizar suas implicações em todos os níveis de sua organização. Eis, portanto, a contribuição do conceito de pluralidade eliasiano: identificar no conjunto das relações e forças sociais elementos estruturantes e instituintes da vida social.

Esse conceito remete, de acordo com Elias e Scotson (2000, p. 184), à ideia da pluralidade de indivíduos ligados por uma rede de relações interdependentes. As configurações são irredutíveis, não havendo como explicá-las em termos que impliquem algum tipo de existência independente dos indivíduos. Os ACSs são um exemplo dessa relação plural, segundo Nunes e colaboradores (2002), por serem membros da comunidade e, ao mesmo tempo, atores do equipamento médico.

Quando trazidas ao campo da saúde, que diferenciações podem estabelecer uma perigosa estrutura hierárquica que impõe dificuldade de acesso às políticas públicas, na perspectiva da saúde da família? Como os ACSs lidam com essas hierarquias, diferenças e configurações sociais específicas?

O ACS, como sujeito inserido no novo modelo assistencial e compondo outro cenário, identificado como nova promoção de saúde, irá se confrontar com fatores tanto gerais como estruturais. Entre os problemas característicos dessa ordem, pode-se destacar: a pobreza, o estresse, as condições precárias de trabalho e de moradia, o envelhecimento populacional, a violência, o isolamento social. Essas questões configuram sociedade e indivíduo como objetos inseparáveis e participantes ativos na transformação da realidade, traduzindo um novo desafio para se enfrentar na área da saúde (Labonte, 1996).

Nesse entendimento de sociedade e indivíduo como mecanismos inseparáveis, ao se pensar o cotidiano do ACS e sua relação com o território e equipe de saúde percebem-se questões que merecem ser discutidas sob a chave dos diferenciais de poder. A própria identidade comunitária do ACS, a partir da visão da equipe mínima, o coloca como executor de tarefas que vão além do campo da saúde (Seabra, Carvalho e Foster, 2008).

No intuito de ratificar as reflexões sobre o fazer profissional do ACS, de acordo com a Política Nacional de Atenção Básica, da portaria n. 2.436, de 21 de setembro de 2017 (Brasil, 2017), que estabelece a revisão de diretrizes para a organização da atenção básica no âmbito do SUS, citemos algumas das atribuições desse profissional: trabalhar com adscrição de indivíduos e famílias em base geográfica definida e cadastrar todas as pessoas de sua área, mantendo os dados atualizados no sistema de informação da atenção básica vigente, utilizando-os de forma sistemática, com apoio da equipe, para a análise da situação de saúde, considerando as características sociais, econômicas, culturais, demográficas e epidemiológicas do território e priorizando as situações 
a serem acompanhadas no planejamento local; utilizar instrumentos para a coleta de informações que apoiem o diagnóstico demográfico e sociocultural da comunidade; desenvolver ações que busquem a integração entre a equipe de saúde e a população adscrita à unidade básica de saúde (UBS), considerando as características e as finalidades do trabalho de acompanhamento de indivíduos e grupos sociais ou coletividades; participar dos processos de regulação a partir da atenção básica para acompanhamento das necessidades dos usuários no que diz respeito a agendamentos ou desistências de consultas e exames solicitados.

Ainda poderão ser consideradas atividades do ACS a serem realizadas em caráter excepcional - assistidas por profissional de saúde de nível superior, membro da equipe, após treinamento específico e fornecimento de equipamentos adequados, em sua base geográfica de atuação, encaminhando o paciente para a unidade de saúde de referência - atribuições como: aferir a pressão arterial, inclusive no domicílio, com o objetivo de promover saúde e prevenir doenças e agravos; realizar técnicas limpas de curativo processadas com material apropriado, água corrente ou soro fisiológico e cobertura estéril, com uso de coberturas passivas, que somente cobrem a ferida; planejar, gerenciar e avaliar as ações desenvolvidas pelos ACSs e agentes de combate às endemias (ACEs) em conjunto com os outros membros da equipe; exercer outras atribuições que sejam de responsabilidade na sua área de atuação.

Tais demandas também se traduzem como um novo desafio para se pensar as ações de saúde, manifestando, portanto, mais uma exigência para o processo de trabalho do ACS.

A população, com seus imensuráveis saberes, com seus grupos coesos, sua autopercepção e reconhecimento sobre como lidar com sua má saúde, requer que profissionais de saúde e pesquisadores do campo, pensem sociedade e indivíduo como objetos inseparáveis e participantes ativos na transformação da realidade dentro de um novo modelo assistencial.

Não obstante, tomando como base os conceitos eliasianos das configurações de uma comunidade, em cuja proposta a ESF se alicerça, somos capazes de visualizar um cenário repleto de contradições, tensões e explosões.

É, pois, nessa esfera de acontecimentos que se encontra o ACS, o qual ainda irá se deparar, além de seu horizonte de atuação, com problemas relativos à pobreza, ao estresse, às condições de trabalho, ao envelhecimento populacional, à violência e ao isolamento social (Labonte, 1996). Em razão disso, tem-se como objetivo a identificação de possíveis diferenças na adesão decorrentes das configurações sociais específicas da população adscrita aos serviços de saúde da família, com base na dimensão concreta da ação dos ACSs, assim como a descrição de sua percepção acerca das diferenças de status, prestígio e poder em seu território de trabalho e espaço de moradia. 


\section{O percurso metodológico}

As reflexões aqui expostas estão associadas aos resultados de pesquisa produzida a partir de um acompanhamento em uma clínica da família do município do Rio de Janeiro. A unidade dispõe de seis equipes de saúde da família, cada uma com cinco ACSs, e duas equipes de saúde bucal.

A metodologia utilizada segue a orientação das chamadas pesquisas qualitativas, valendo-se de técnicas socioetnográficas, com o emprego de observação, mapeamento participativo, diário de campo e registros complementares como entrevistas semiestruturadas, individuais e coletivas.

Em um universo de trinta ACSs, foram gravadas dez entrevistas, transcritas, com tempo estimado de uma hora de duração. Para interpretação, as entrevistas foram submetidas às técnicas de análise das sinopses das configurações sociais específicas de Elias e Scotson (2000).

Ao se sustentar no paradigma das configurações sociais específicas construídas em um determinado território, com base na obra Os estabelecidos e os outsiders, dos sociólogos Norbert Elias e John L. Scotson (2000), foram considerados todos os aspectos relevantes sobre a prática do trabalho etnográfico, assim como o modelo utilizado pelos autores para elucidar outras configurações mais complexas. Com isso, foi possível compreender melhor as características estruturais em comum e as motivações que funcionam e se desenvolvem segundo orientações diversas, de acordo com as condições enfrentadas.

A observação e a sinopse das configurações sociais especificas objetivam ir além das análises quantitativas e estatísticas e consubstanciam a existência de grupos e subgrupos que, de outra forma, não se destacariam na pesquisa - atingindo, desse modo, melhor compreensão das relações existentes, ou seja, peculiaridades que poderiam ser camufladas por outras mais acentuadas como cor e classe social.

Desse modo, consideramos que no campo da saúde, esfera na qual é preciso pensar nas peculiaridades das relações existentes, não podemos deixar de chamar a atenção para a reestruturação dos processos de trabalho e a potencialização do 'trabalho vivo em ato'. Ao viver em sociedade, mantém-se o posicionamento sempre em coletivo, tendo as atividades também reorganizadas de acordo umas com as outras. Tal exercício, porém, modifica a forma de pensar e de agir em sociedade (Merhy e Franco, 2005).

$\mathrm{O}$ traçado da pesquisa teve como primeiro momento a participação em uma reunião técnica que acontece uma vez por semana na clínica e conta com a presença do gestor, de enfermeiros e técnicos de enfermagem. Na ocasião, foi apresentado o trabalho a ser realizado, assim como agendamentos diversos, observações sobre mapeamento participativo, diário de campo e registros complementares, entrevistas semiestruturadas, individuais e coletivas. 
Ao longo da apresentação, percebeu-se que alguns chefes de equipes técnicas sinalizavam dificuldade para 'liberar' os ACSs para as entrevistas. O fluxo de atividades realizadas por esses profissionais fora da unidade de saúde dificulta, na visão de alguns chefes de equipes de saúde, a disponibilidade para responder a entrevistas ou mesmo participar de atividades, ainda que estas estejam voltadas à temática de sua prática de trabalho. Apesar da resistência, optou-se por seguir com a agenda previamente programada na gestão da unidade.

Na ocasião da segunda apresentação, confirmaram-se as primeiras impressões acerca das barreiras apresentadas. $\mathrm{O}$ número de profissionais presentes (médicos, enfermeiros, técnicos de enfermagem) foi moderado, assim como o número de ACSs que não haviam participado da reunião anterior.

A apresentação do trabalho, depois de respondidas as dúvidas expostas, pareceu naquele momento suficiente para despertar nos chefes de equipe o entusiasmo e o comprometimento para a realização da pesquisa e, dessa forma, contribuir não apenas para o desenvolvimento do estudo em pauta, mas também para a melhoria do processo de trabalho entre ACSs, equipes de saúde e população usuária. Tal avaliação revelou-se mais um equívoco.

Desde os primeiros contatos com os ACSs, houve a sensação de que a pesquisa seria encarada como uma 'tradução' das ansiedades desses profissionais. $\mathrm{O}$ fato de a pesquisadora em campo ser assistente social talvez tenha favorecido uma postura mais tranquila e receptiva dos profissionais, que se permitiram desabafar sobre suas aflições.

O perfil profissional possibilitou, no decorrer da coleta de dados, identificação e tranquilidade dos entrevistados para exporem suas concepções e sentimentos, uma vez que é exigida do assistente social a capacidade de perceber necessidades, problemas e emoções, preferências e maneiras de pensar do indivíduo e daquilo que ele é e deseja ser, mas também de perceber aquilo que não se vê. Além disso, houve a necessidade de se debruçar sobre a produção de um conhecimento crítico da realidade social, assim como aprofundar o diálogo crítico e construtivo com diversos ramos das chamadas ciências humanas e sociais.

Nesse enfoque, a percepção do ACS para além do número de entrevistados trouxe a oportunidade de observar como essa figura pode se misturar e se confundir, em seu fazer profissional, com tudo o que a ESF preconiza de forma geral. Há um sentimento de ambiguidade no que se refere à figura desse profissional.

\section{As entrevistas semiestruturadas}

No conjunto total de ACSs entrevistados, quase na totalidade era do sexo masculino, na faixa etária entre 28 e 60 anos; grande parte declarou afiliação religiosa evangélica; a formação mais declarada foi ensino médio completo. 
Todos os entrevistados possuíam o mesmo tipo de vínculo empregatício, em regime celetista, com contratos estabelecidos com a organização social de saúde (OSS) Viva Rio. A carga horária desses profissionais era de quarenta horas semanais.

O tempo médio de experiência como ACS na ESF era de aproximadamente cinco anos. $\mathrm{O}$ menor tempo de atuação foi de nove meses.

Perguntados sobre o porquê da escolha de ser ACS, nove pessoas responderam que não havia sido uma escolha, mas uma necessidade, já que se encontravam desempregadas. Desse total, quatro afirmaram ter passado a se identificar com o serviço após iniciar a prática.

Nesse universo de imprecisão, pode-se citar o vínculo criado entre ACS e população, mas sem deixar de considerar questões éticas e sigilosas que perpassam essas relações, sendo este um aspecto que demanda privacidade. Sobre essa problemática, Fortes e Spinetti (2004) dizem tratar-se de um elemento outrora inexistente, quando se referem a esse novo modelo assistencial. Contudo, eles vão além do debate já estabelecido por outros autores que se debruçam sobre o enfoque do papel do ACS e a acessibilidade do prontuário médico. Os autores mostram, em seu estudo, uma compreensão da questão do sigilo e da ética, mais como forma de preservação do ACS como morador de determinado território. A função do ACS pode ser temporária; no entanto, ele continuará sendo morador e vizinho.

Ao descreverem alguns usuários como 'amigos ou inimigos', a título de exemplo, o vínculo de confiança estabelecida pode se fortalecer ou fragilizar de acordo com a mudança das relações entre profissional e população usuária.

\section{O diário de campo: experiências e reflexões quanto ao acesso aos serviços de saúde}

O momento seguinte englobou a participação em pequenas rodas de conversa com os usuários no próprio território. Sobre o serviço ofertado pela ESF, as falas repetiram-se no que acabou se caracterizando como 'marginalização do serviço'. Constatou-se que a população mais vulnerável social e economicamente precisa do serviço, mas não acredita em sua eficácia, além de associar a utilização do aparato ao status social e econômico.

Avaliou-se a ESF como elemento integrante da reorganização do modelo assistencial de saúde no Brasil. Essa concepção brasileira de atenção primária à saúde afina-se com a definição defendida por Starfield (2002), que assegura o acesso ao sistema de saúde, aos dados relativos à satisfação dos usuários e o aumento da efetividade e eficiência da atenção sanitária. Para os grupos que participaram das rodas de conversa, a acessibilidade aos serviços ofertados pela ESF deveria ser experimentada de forma mais interativa. Essa interação 
compreende o comportamento dos indivíduos, os serviços disponíveis e os profissionais de saúde (Travassos e Martins, 2004).

A ESF funciona como porta de entrada, com base em trabalhos que avaliam a acessibilidade, mas demonstram fragilidade, principalmente no que diz respeito aos aspectos estruturais e processuais. Segundo Travassos e Martins (2004), faz-se necessário obter mais informações sobre questões referentes à organização e ao uso de serviços de atenção primária em saúde, mas também que se considere a perspectiva de usuários, profissionais e gestores.

Nesse enfoque, destaca-se a fala de alguns usuários sobre o fato de se sentirem 'marginalizados' e serem alvos de 'fofoca' quando necessitam acessar os serviços da ESF. Para esse grupo, tanto os profissionais quanto alguns moradores de vilas e condomínios consideram os usuários como pessoas inferiores. São vistos como 'barraqueiros', incapazes de 'se comportarem como pessoas educadas'.

Nesse tipo de figuração social, grupos considerados outsiders têm sua autoimagem desprestigiada quando são alvos de fofocas depreciativas (blamegossip) (Elias e Scotson, 2000). Tal estratégia por parte dos grupos estabelecidos ilustra a responsabilidade dos outsiders como censura de algumas de suas próprias atitudes.

\section{A caracterização do mapa falante e o desafio do lugar de 'fora' do ACS}

A técnica de mapeamento do território ou mapa falante caracteriza-se como uma possibilidade de conhecer não só os equipamentos sociais existentes no território, mas também suas potencialidades, desafios e subjetividades. $\mathrm{O}$ mapeamento deve ser compreendido como o processo de coleta e registro de informações e percepções da comunidade sobre o território em que se vive e convive. Destina-se a produzir informações que possam ser disponibilizadas e consultadas de forma ágil e dinâmica mediante uma base cartográfica que permita a visualização do território e suas interações, sendo estas constantemente atualizadas (Cedaps, 2009).

Com esse propósito, realizou-se uma oficina presencial com dez elementos, em um universo de trinta ACSs, na própria unidade de clínica de saúde da família. A atividade teve quatro horas de duração. Para maior qualidade de coleta inicial de informações, oficinas desse tipo devem durar em média oito horas; todavia, o tempo disponibilizado pelas equipes de saúde para que os ACSs participassem foi apenas de um turno.

A presença do facilitador na atividade serviu para orientar a atividade do grupo, assim como para se apresentar como um agente externo à comunidade. O objetivo era que o facilitador viesse a conhecer o território, no caso do estudo em foco, os principais recursos disponíveis (públicos, sociais, comerciais, informais etc.) e problemas existentes, sobretudo com enfoque nas configurações sociais específicas das microáreas em que atuava. O grupo, 
nesse caso composto pelos ACSs, deveria transmitir as informações de forma objetiva e compreensível.

Antes do início das atividades propriamente ditas, foi realizada uma breve apresentação do projeto para que houvesse um entendimento por parte dos ACSs sobre o conceito de 'território', seguida de orientações sobre como realizar um levantamento que atendesse aos objetivos da pesquisa desenvolvida.

A despeito de ter sido agendada e divulgada com bastante antecedência por parte dos gestores da clínica a todas as equipes de saúde, a fim de liberarem os ACSs para a realização da atividade, informou-se a impossibilidade de alguns estarem presentes por terem numerosas atividades naquele dia fora da clínica. Alguns agentes expressaram frustração por não terem sido liberados pelos chefes de equipe. O seu lugar constantemente era remetido ao 'estar na rua'. O 'fora' era o seu lugar de pertencimento. As oficinas, os espaços de problematização para se discutirem os tensionamentos produzidos em seu próprio processo de trabalho pareciam criar um certo estranhamento tanto para as equipes quanto para os próprios ACSs.

\section{Choque de realidade entre o mapa oficial e o mapa real: discutindo o mapeamento}

Os principais desafios trazidos pelos ACSs após a construção dos mapas falantes foram as limitações nas relações estabelecidas entre equipe técnica, ACSs e população usuária; a importância de se estar alerta para os movimentos da vida comunitária; o desconhecimento de emergências do cotidiano que chegam até os serviços de saúde e quais enfrentamentos feitos pelas equipes de saúde; o desconhecimento da própria microárea de atuação e a microárea de atuação de colegas; a ausência de articulação com outras políticas sociais como assistência social, educação, segurança; o desconhecimento das redes informais do território como instituições religiosas, organizações não governamentais (ONGs), entre outras.

Pode-se dizer que a discussão sobre o mapeamento daquele território sinalizou, em grande medida, para alguns embates em torno da precária noção administrativa que se tem de território. Monken e Barcelos (2007) alertam para o fato de que a precariedade dessa noção distancia as ações da realidade e impede a perspectiva da participação social.

Sobre a relação entre equipe de saúde e usuário na perspectiva dos ACSs, as divergências ocorrem a respeito das orientações e informações recebidas por outros profissionais da equipe e repassadas pelos agentes durante as visitas domiciliares. Baralhas e Pereira (2013) destacam a importância do acolhimento, do vínculo e da humanização nos serviços e relacionam a ausência dessas práticas no atendimento dos demais profissionais da UBS, o que dificulta a efetivação das suas ações. 
O desenvolvimento da técnica de mapeamento do território fomentou, sobretudo, não só a possibilidade de se conhecerem os equipamentos sociais existentes, mas também a necessidade de se discutir o conceito de integralidade, que parte do princípio de compreender as necessidades de saúde e a potencialidade de ajuda dos trabalhadores/equipes/serviços/rede de serviços, assim como favorecer melhor escuta das pessoas que buscam cuidados em saúde, tomando suas necessidades como centro de suas intervenções e práticas (Cecílio, 2001).

\section{Resultados: significados que o ACS confere à sua prática}

O conhecimento sobre o papel do ACS objetivou inteirar-se do significado que o agente comunitário confere à sua prática no processo de construção da ESF. Tal percepção, em alguma medida, manifestou o grau de qualificação a que esse profissional foi exposto para desenvolver as funções necessárias para o satisfatório exercício de seu papel. Esse dado é importante porque revelou elementos consideráveis, uma vez que se pretendeu descrever a percepção do ACS acerca das diferenças de status, prestígio e poder em seu território de trabalho e espaço de moradia.

Como refere a PNAB 2017 (Brasil, 2017) sobre o conhecimento e a apreensão dos ACSs sobre seu papel, mais de $50 \%$ dos entrevistados demonstraram não terem certeza sobre suas atribuições, apresentando alguns conceitos inadequados tais como:

Acho que o papel do ACS é ajudar as pessoas, mas também acho que para ajudar precisamos ter a técnica, né? A gente enfrenta problemas no território que me faz pensar qual é o meu papel... são tantos que nem sei mais (ACS 1).

Orientar a população. A população precisa entender que o que estamos oferecendo é o melhor para elas. A população às vezes não quer aceitar nosso papel (ACS 2).

Eu meio que sou vigilante... (risos) Tenho que vigiar e orientar. Às vezes, vejo que não é só isso, mas não sei bem como deve ser (ACS 3).

\section{Formação profissional do ACS}

De acordo com Gomes e colaboradores (2009), essa dificuldade para entender o seu papel dentro da ESF e o seu funcionamento pode estar relacionada à formação profissional. Há diversos trabalhos que ressaltam o fato da formação do ACS permanecer focada no controle da doença, o que acaba por repetir a visão segmentada e reducionista do padrão biomédico em sua prática (Gomes et al., 2009). 
Dessa forma, tornam-se substanciais, segundo Noronha e colaboradores (2009), a formação e a educação permanente da equipe multiprofissional, seja na assistência, seja no planejamento ou na programação de suas ações.

Quanto à preparação para atuar como ACS segundo a lógica a que se propõe a ESF, apenas um dos entrevistados recebeu capacitação - que, segundo sua opinião, não foi satisfatória, como relatou:

Olha só, tive um ensinamento muito curto... praticamente nada. [...] Então tem que se adequar às situações e aprendo assim. Não tivemos uma, é... ensinamento, um curso. Foi coisa de um dia. Uma conversa (ACS 1).

Os demais, como mostraram alguns relatos, não receberam nenhum tipo de capacitação.

Assim: [...] ninguém aqui recebeu uma capacitação adequada. Por lei nós deveríamos ter o curso de ACS. [...] Ninguém na unidade tem. [...] não conseguimos fazer a inscrição, não conseguimos acesso às vagas. Já tentei pelas vias normais, já tentei [...] diretamente falando com os coordenadores... (ACS 2).

Não. Já tentei fazer o curso, mas não consegui. Porque eles falam que a vaga é contada, e sempre que abre curso já tem gente para fazer (ACS 1).

A única capacitação foi a da amamentação. A única que eu tive. Nem para entrar eu tive. Todos os outros colegas aqui da clínica já tiveram a iniciação, que foram os três dias de treinamento que eles falam. Que mostra como é o sistema. Eu não. Eu caí de paraquedas já na equipe. [...] Caí de paraquedas na guerra mesmo e estou aí até hoje. Me virando, aprendendo com quem quer ensinar; quem não quer ensinar eu dou meu jeito para poder aprender (ACS 2).

O fato é que o ACS deveria ser qualificado com relação aos diversos aspectos que envolvem o processo saúde/doença. Porém, quando essa capacitação acontece, parece ser conduzida por um paradigma que privilegia os aspectos biológicos, desconsiderando, inclusive, as orientações previstas pelo Ministério da Saúde no que se refere às competências desse profissional.

Os programas educacionais dos ACSs devem ser compostos e fundamentados para desenvolver competências. Os métodos utilizados de ensino-aprendizagem precisam ser inovadores, reflexivos e críticos, centrados no estudante. Para Tomaz (2002), a possibilidade de inclusão de novas tecnologias também necessita ser considerada, assim como, de acordo com o contexto, o desenvolvimento de algumas competências transversais. A predisposição para a comunicação e o trabalho em equipe tem que fazer parte de qualquer programa que pretenda qualificar o ACS ou mesmo outros profissionais de saúde. 
Parreiras e Martins Jr. (2004) põem em pauta uma discussão sobre estarmos caminhando para um novo paradigma que, embora não tenha a intenção de suprimir antigas práticas, torna necessário o debate no campo do conhecimento, da educação e da saúde. Eles nomeiam tal modelo como paradigma técnico e reflexivo. Este paradigma não se constitui em um encadeamento de ruptura, mas de sequência, em que na convivência vão surgindo as tendências diferenciadoras.

O paradigma técnico, de acordo com os autores, diz respeito à biomedicina, em que a base sustentadora de atuação é a ausência de doença como definição de saúde. Tal modelo se concentra no indivíduo e na doença em uma visão hospitalocêntrica dominante. O principal profissional interventor é o médico, em uma prática especializada, desagregada da atenção sobre o ser humano. O principal enfoque da prática desse paradigma volta-se para a ótica da prevenção e assistência à saúde.

Entretanto, um dado que também ficou evidente foi a vontade que aparentemente os ACSs manifestaram em aprender e se profissionalizar.

\section{A relação do ACS com usuário/comunidade e as dificuldades encontradas no que se refere à adesão da população adscrita}

Todos os entrevistados sinalizaram haver algum tipo de situação geradora de dificuldades que impedem a adesão da população adscrita aos serviços ofertados pela clínica da família, assim como a identificação de grupos com diferenças de poder e prestígio. Aspectos religiosos também foram apresentados como fator de dificuldade na adesão de algumas famílias aos serviços de saúde. Embora esse ponto de vista tenha sido defendido por outros entrevistados, três apontaram a citada perspectiva de maneira mais enfática:

É muito difícil fazer adesão com pessoas que tratam a doença de outras formas, né? Assim, eu sou cristão protestante, defendo minha fé quando me convém. Em meu horário de trabalho sou um funcionário, mas encontro famílias que recorrem à religião e não recorrendo para a saúde. Elas preferem ir para uma igreja, preferem ir num centro, preferem ir no seja lá o que for, buscar uma orientação religiosa, um milagre religioso, e não buscam a saúde (ACS 1).

Há um cadastrado espiritualista... está com câncer. [...] E ela falou que a vizinha dela ficou curada de um câncer no útero indo num determinado local, usando uma devida coisa que davam lá. [...] ela veio me consultar como ACS. Às vezes, por falta de estrutura, de alguém que pudesse dar uma visão a ela [...] (ACS 2).

Eu perguntei a ela: você crê nisso, que você vai conseguir isso, que sua mãe vai ter uma melhora, que pode não ser uma cura total, mas vai ter uma melhora? Ela 
[falou:] 'Creio.' [Respondi:] 'Então vai com fé.' o que eu poderia dizer? Eu nem tinha o que dizer... Nem levei isso para a equipe. Por um acaso fomos capacitados para lidar com isso? (ACS 3).

Percebe-se aqui que o aspecto cultural e religioso, decorrente das configurações sociais específicas do território, pode provocar possíveis diferenças na adesão ao serviço de saúde da família. Outra questão exposta apontou a precária interação dentro das equipes e despreparo para lidar com as questões subjetivas nas práticas de atenção.

\section{O desejável nó entre o sistema de cuidados de saúde e a conformação social de um território}

De acordo com Helman (2009), o sistema de cuidados de saúde de qualquer sociedade não pode ser entendido de forma isolada, sem se considerarem outros aspectos dessa sociedade. O sistema se entrelaça a esses outros aspectos, especialmente os relacionados à organização social, religiosa, política e econômica. Essa textura finda por se sustentar nos mesmos valores, presunções e visões de mundo.

Um sistema de cuidados de saúde, de acordo com o autor, tem dois aspectos que se inter-relacionam: o aspecto cultural, que compreende algumas formulações básicas, teorias, práticas normativas e modos compartilhados de concepção; e o aspecto social, que apresenta determinados papéis específicos (como médico e paciente) e normas que comandam as relações entre esses papéis (Helman, 2009).

Pessoas que enfrentam alguma doença vão ao encontro de várias formas de assistência em busca de solução e diagnóstico, na ânsia de obterem algum alívio. As sociedades ocidentais, contudo, em sua maioria, adotam uma forma de cuidados de saúde alçada acima das outras formas. Há sistemas alternativos menores que, de acordo com Helman (2009), são identificados como 'subculturas de cuidados da saúde'. Cada indivíduo terá sua própria maneira de explicar a má saúde e tratar dela. Os agentes de curas, em cada grupo profissional que se organiza, devem oferecer modos diferentes de relacionamento com esses usuários. Para o autor, há um pluralismo dos cuidados de saúde que tem a ver com uma série de alternativas de assistência de saúde a serem ofertadas à população.

Helman (2009) apresenta ainda algumas variedades de opções terapêuticas disponíveis em nossa sociedade. A alternativa informal é uma delas, em que a família do indivíduo doente é o primeiro grupo de assistência de saúde. Nesses grupos familiares, as mulheres, principalmente mães e avós, tornam-se os principais agentes. São elas que diagnosticam e utilizam os materiais disponíveis.

A automedicação também surge como um recurso informal e normalmente orientada por amigos, vizinhos e outras pessoas que já fizeram uso de 
medicamentos em algum momento de suas vidas. Segundo o autor, no Reino Unido é bastante comum a troca de medicamentos industrializados. Grupo de autoajuda é outro exemplo informal de assistência, como associações de enxaqueca, depressivos, comando gay e organização pela saúde da mulher.

Na leitura de Helman (2009), a biomedicina como ideologia de cura, ainda que seja uma concepção dominante, vem enfrentando uma crise. Tal fenômeno ocorre a despeito dos inúmeros sucessos na prevenção e tratamento de doenças, alívio do sofrimento e aumento da expectativa de vida. Nos últimos anos, de acordo com o autor, nota-se uma crescente insatisfação das populações, que se traduz em aumento de queixas contra médicos e maior popularidade dos tratamentos alternativos.

O fato de as pessoas viverem cada vez mais acaba por demandar cuidados que envolvem períodos mais longos. Indivíduos com hipertensão, diabetes e outras situações consideradas crônicas precisam se tornar corresponsáveis pelo seu tratamento. Esses pacientes deverão monitorar sua própria condição tratando a si mesmos em parceria com os profissionais de saúde.

No Brasil, a Organização Mundial da Saúde (OMS) recomendou, em 2006, a Política Nacional de Práticas Integrativas e Complementares no SUS (PNPIC), no intuito de favorecer a implantação e adequação de ações e serviços, além de promover as ações referentes ao controle e participação social, promovendo o envolvimento responsável e continuado dos usuários, gestores e trabalhadores nas diferentes instâncias de efetivação das políticas de saúde (Brasil, 2015).

\section{A área urbana e os novos desafios para o ACS}

Parece lógico e plausível que, associado às questões aqui anunciadas, de acordo com Baralhas e Pereira (2013), o trabalho dos ACSs desenvolvido principalmente em área urbana seja permeado por novos desafios. Violência urbana, tráfico de drogas, desemprego e outros fatores são realidades que transpassam o território de saúde e requisitam uma ação intersetorial mais efetiva. O relato a seguir caracteriza algumas dessas configurações em relação às quais as equipes de saúde necessitam fazer enfrentamento.

A dificuldade que mais encontro é com as famílias que moram nos prédios. Elas não aceitam muito o serviço da clínica, mas também por causa do pessoal do Chapadinho. Eles [pessoal dos prédios e condomínios] já vivem aqui há muitos anos. [...] Porque assim, essa região, por ser um conjunto da Marinha, às vezes o pai de uma família era oficial e o pai da outra era cabo, sargento, praça. [...] Então assim, tem trechos da rua que você fala: 'nossa, é muito diferente' [...] por exemplo, o do 200 me trata maravilhosamente bem, o do 199 não me trata bem. Mas você fala: 'por que isso?' Porque o vizinho do 200 era parente do cabo... E ele te enxerga não 
só como um profissional, mas como um possível amigo, uma pessoa com a qual você tem condição de conversar. Agora, o vizinho do 199 ele acha que, por ter parente que foi oficial, acha que tem ainda muito dinheiro para ter que falar com você (ACS 1).

Ele não usa a clínica da família. Ele até tem condições de pagar um plano barato de saúde, mas no fim tá tudo igual com o outro. Não aceitam se cadastrar porque acham que vão parecer pobres (ACS 1).

Em sua abordagem, Elias e Scotson (2000) alertam para a possível estigmatização dos indivíduos de um grupo por membros de outro grupo, não devido a suas características pessoais, mas por fazerem parte de um outro grupo que de forma coletiva é considerado diferente e inferior. Para os autores, é de fundamental importância que, ao se pensar em 'preconceito social', deve-se ampliar suas causas, já que comumente ele é explorado apenas pela via da personalidade dos indivíduos.

[...] a comunidade do Chapadinho... o pessoal dos condomínios não quer o nome da equipe 'Chapadinho'. Eles não gostam de se misturar, e eu entendo. O pessoal dos condomínios não quer ficar perto do pessoal do 'Chapadinho'. Sabe por quê? Os do 'Chapadinho', até nas roupas, são chamativos. Adoram falar alto e brigam muito. Nem se compara aos dos condomínios. O pessoal dos condomínios não tem muita coisa mais, mas eles já tiveram, né? Ficam com vergonha. Na escola e até no mercadinho é a mesma coisa (ACS 1).

Na perspectiva de Elias e Scotson (2002), a estigmatização só pode ser encontrada caso se leve em consideração a figuração formada por grupos que são interdependentes. Essa expressão tem como ponto fulcral, de acordo com os autores, o equilíbrio instável de poder com suas tensões naturais. Um grupo só pode estigmatizar outro de forma operativa quando se sente instalado em uma posição de poder, da qual o outro estigmatizado é excluído. Atribuir o estereótipo de 'valor humano inferior' a outro grupo é uma estratégia bastante utilizada por grupos que se reconhecem como superiores. É o meio de manter a superioridade social.

A autoimagem do grupo socialmente menos poderoso também pode se enfraquecer, já que grupos menos coesos tendem a não se sujeitarem a padrões específicos de controle (roupas menos chamativas, tom de voz moderado, atitudes mais pacatas e cordatas). O grupo de moradores do 'Chapadinho', por não se submeter às normas dos moradores das vilas e dos condomínios, rompe, de certa forma, com as regras estabelecidas pelo grupo de maior poder social. 
Todos os grupos sociais estipulam regras e tentam, em alguns momentos e circunstâncias, de acordo com Becker (1977) em seu estudo Uma teoria da ação coletiva, fazer com que essas regras sejam seguidas. Durante os primeiros contatos com os ACSs do território, foram obtidos relatos sobre a relação tensa entre os moradores mais antigos, dos condomínios, e os do complexo do Chapadinho, uma ocupação posterior.

Os moradores dos condomínios e vilas, por estarem no território há mais tempo, percebem-se superiores, tanto socialmente quanto no aspecto de antiguidade no território, e acreditam que os moradores do entorno, mesmo os pertencentes ao território de abrangência, não merecem ter o mesmo direito de acesso aos serviços ofertados pela unidade de saúde.

Todavia, outras questões foram se apresentando, como confirma a fala do entrevistado ao se referir aos moradores dos condomínios como pessoas que 'não gostam de se misturar' com os moradores do Chapadinho pelo fato de estes não seguirem as regras sociais dos primeiros.

Regras sociais, de acordo com Becker (1977), definem situações sociais e os tipos de comportamentos apropriados. No relato do entrevistado, os moradores do complexo do Chapadinho são percebidos como um grupo não cumpridor dessas regras.

Essas possíveis diferenças encontradas no cenário descrito pelos entrevistados acabam por afetar a adesão aos serviços de saúde da família, pois o grupo morador dos condomínios não aceita ser inserido como usuário cadastrado na mesma equipe de saúde do grupo morador do Chapadinho. O relato a seguir clarifica como se dá essa relação conflituosa.

Tem família nos condomínios que estão todos sem plano bom, mas eles não querem o ACS na porta para não 'passar vergonha com os vizinhos'. Se a gente chega e chama a pessoa, todos os vizinhos vêm olhar. Dá vergonha, né? A pessoa tinha plano bom... Agora é SUS. Daí eles vêm aqui, pra gente não ir lá, e ficam sabendo que o nome da equipe deles é Chapadinho. [...] O pessoal do Chapadinho acha bom. Não querem que mude o nome. Quando se encontram aqui na clínica, é problema: os do 'Chapadinho' com os dos 'condomínios' (ACS 1).

O problema é que o pessoal do Chapadinho [...] alguns, né?, possuem aqueles planos vagabundos, mas não se importam de usar o SUS. Alguns dos condomínios usam também esses 'planinhos', mas têm vergonha de usar o SUS. O 'planinho' não cobre tudo, sabe? Mas ainda assim têm vergonha. Não dá para entender.. Todo mundo no mesmo balaio de gatos (ACS 2).

\section{Considerações finais: a difícil tarefa de encontrar as diferenciações sociais}

Entender a dinâmica da estigmatização não é tarefa fácil. É preciso que se apurem de forma concreta as características do papel que cada indivíduo de- 
sempenha, como ele enxerga a posição de seu grupo entre outros e, consequentemente, seu próprio status como membro desse grupo (Elias e Scotson, 2000).

Os moradores dos condomínios mencionados, estando há mais tempo no território, tinham uma imagem do 'eu' e uma imagem de 'nós', como grupo dominante, muito bem estabelecida. Os relatos dos entrevistados, contudo, também revelaram diferenciações entre os 'dominantes' - isto é, intragrupo - no que diz respeito ao grau de status e prestígio.

Alguns moradores ainda apresentavam poder aquisitivo para obter planos de saúde, enquanto outros perderam essa capacidade. Tal perda de poder econômico relativo reflete-se no status do morador que se sente 'envergonhado' perante o vizinho, pelo fato de este poder pagar por um plano de saúde, ainda que não cubra todas as suas necessidades de saúde.

$\mathrm{O}$ fato é que a maioria dos moradores dos condomínios daquele bairro perdeu, ao longo do tempo, a capacidade de obter planos de saúde de valor elevado. Poucos conseguem adquirir planos de saúde mais populares. Conquanto, quando se trata de estigmatizar os moradores do Chapadinho, há um movimento de coesão, por parte dos moradores dos condomínios, que finda por dissolver as diferenciações existentes.

A relação estabelecidos/outsiders, formada por esses dois grupos, representa a coesão grupal dos moradores dos condomínios no que se refere aos moradores do Chapadinho. Assim como em Winston Parva, verificou-se uma barreira emocional construída entre dois grupos de moradores do bairro da Pavuna que fazia com que o contato mais estreito, pelo fato de pertencerem à mesma equipe de saúde, se tornasse conflituoso, apesar de a superioridade social de um grupo sobre o outro apresentar-se minimizada pelo compartilhamento de um mesmo serviço de saúde.

Os moradores dos condomínios, ao rejeitarem aderir aos serviços de saúde da clínica da família do território e por se considerarem superiores aos moradores do Chapadinho, promoviam um quadro capaz de comprometer a qualidade do atendimento e cobertura da política pública.

Os preconceitos, tidos como aparentemente banais e como parte do cotidiano das coletividades, podem estabelecer uma condição de organização que finda por dificultar o acesso às e pelas políticas públicas, na perspectiva da saúde coletiva. Mais uma vez, reitera-se a questão sobre como as equipes de saúde, por exemplo, lidam com essas hierarquias, diferenças e configurações sociais específicas.

Ao se considerarem essas questões, o padrão de respostas dos indivíduos questionados, ao longo das entrevistas, principalmente no que se referia às configurações dos territórios onde se localizam os condomínios e o complexo do Chapadinho, foi se tornando repetitivo. Assim como observado em Winston Parva, os entrevistados da Clínica da Família Epitácio Soares Reis também não expressavam ideias próprias, mas as concepções incorporadas às crenças e condutas que permeiam a visão do ACS sobre a vida dos moradores. 
Percebeu-se, ao longo das entrevistas realizadas com os ACSs, que as respostas foram tomando um rumo cujas ideias-padrão sobrepunham-se às opiniões individuais que se deslocavam desses padrões. Confrontou-se, então, uma situação análoga vivida por Elias e Scotson (2000), ao conferirem que em uma comunidade estreitamente unida as pessoas tendem a apresentar uma conduta idêntica.

Diante desse panorama, reconhece-se que o grupo de ACSs entrevistado também passou a adotar uma postura idêntica, com repetições de respostas que mostraram o desejo de passar uma impressão de concordância grupal. Ainda que em alguns momentos as respostas dadas apresentassem uma visão mais pessoal e diferenciada sobre o que estava sendo questionado, rapidamente voltavam a um padrão que preponderava no grupo.

Dessa forma, com base na identificação das relações de poder, dependência e exclusão existentes no território pesquisado, tanto quanto os níveis de organização e aspectos de vida dos usuários na ótica dos ACSs, foi possível apreender a existência de grupos e subgrupos que, de outra forma, não se evidenciariam, atingindo-se assim melhor compreensão das relações ali existentes.

O processo realizado resultou na possibilidade de se identificarem possíveis diferenças na adesão decorrentes das configurações sociais específicas da população adscrita aos serviços de saúde da Clínica da Família Epitácio Soares Reis, mediante a dimensão concreta da ação dos ACSs; assim como a percepção do agente comunitário acerca das diferenças de status, prestígio e poder em seu território de trabalho e espaço de moradia. Na mesma conformação, houve a identificação de problemas existentes na relação entre equipe de saúde e usuário na ótica do ACS, e que tais conflitos podem provocar viés no desenvolvimento das políticas.

Este estudo, dentro de seus limites, trouxe algumas contribuições para maior conhecimento da ação do ACS na sua relação com a qualidade do serviço e da cobertura prestada pela ESF, e apontou para possíveis diferenças na adesão da população adscrita aos serviços de saúde da família mediante a dimensão concreta da ação dos agentes comunitários em diferentes configurações sociais. Resta especular se outras variáveis, além da dimensão socioeconômica, produziriam implicações importantes para o exercício do trabalho do ACS e, em termos gerais, para o sucesso da atenção primária à saúde.

\section{Financiamento}

Este suplemento "Educação e Trabalho em Saúde: diálogos e experiências no Brasil e em Portugal" foi realizado com apoio da Coordenação de Aperfeiçoamento de Pessoal de Nível Superior (Capes) - Código de Financiamento 001; e do Departamento de Pesquisa em História das Ciências e da Saúde da Casa de Oswaldo Cruz (Depes/COC/Fiocruz, 6151000000). Todos os autores declaram que não há conflito de interesses. 


\section{Colaboradores}

Cintya Cristine Martins da Veiga Faria realizou trabalho de campo, análise e redação do artigo. Carlos Henrique Assunção Paiva realizou análise e redação do artigo.

\section{EL TRABAJO DEL AGENTE COMUNITARIO DE SALUD Y LA COMPRENSIÓN DE LAS DIFERENCIACIONES SOCIALES DENTRO DEL TERRITORIO}

Resumen En el artículo discutimos las diferenciaciones sociales presentadas como desafíos para el agente comunitario de salud en su trabajo diario. El estudio consistió en analizar las configuraciones sociales construidas en el territorio adscrito, a partir de la acción de los agentes comunitarios de salud. Se destacan las herramientas analíticas que permiten comprender los distintos padrones de estratificación social entre grupos que pertenecen al mismo entorno socioeconómico. El método de investigación adoptado se basó en el enfoque cualitativo por medio de diez entrevistas semiestructuradas y seguimiento junto a una clínica de la familia, de la municipalidad del Rio de Janeiro, en 2016 y 2017, utilizando técnicas socio-etnográficas. Los resultados apuntan a la existencia de dificultades que impiden la adhesión de la población adscrita a los servicios ofertados por la clínica de la familia, así como la identificación de grupos con diferencias de poder y prestigio. Se reitera la cuestión de cómo los equipos de salud tratan con entornos sociales específicos. Se concluye que las relaciones establecidas en el espacio que circunscribe las unidades de salud de la familia necesitan ser constantemente monitorizadas para identificar posibles diferencias en la adhesión resultantes de las configuraciones sociales específicas de la población adscrita a los servicios de salud.

Palabras clave agentes comunitarios de salud; trabajo; adhesión; configuraciones sociales específicas; territorios de salud. 


\section{Referências}

BARALHAS, Marilisa; PEREIRA, Maria A. O. Prática diária dos agentes comunitários de saúde: dificuldades e limitações da assistência. Revista Brasileira de Enfermagem, Brasília, v. 66 , n. 3, p. 358-365, maio-jun. 2013.

BECKER, Howard S. Uma teoria da ação coletiva. Rio de Janeiro: Zahar Editores, 1977.

BRASIL. Ministério da Saúde. Secretaria de Atenção à Saúde. Departamento de Atenção Básica. Política nacional de práticas integrativas e complementares no SUS : atitude de ampliação de acesso / Ministério da Saúde. Secretaria de Atenção à Saúde. Departamento de Atenção Básica. - 2. ed. - Brasília: Ministério da Saúde, 2015. Disponível em: <http://bvsms.saude.gov. br/bvs/publicacoes/politica_nacional_praticas_integrativas_complementares_2ed.pdf $>$. Acesso em: 15 maio 2016.

BRASIL. Ministério da Saúde. Política Nacional de Atenção Básica 2017. Disponível em: < http:// bvsms.saude.gov.br/bvs/saudelegis/gm/2017/ prt2436_22_17.html>. Acesso em: 10 maio 2016.

CECÍLIO, Luiz C. O. As necessidades de saúde como conceito estruturante na luta pela integralidade e equidade na atenção em saúde. In: PINHEIRO, Roseni; MATTOS, Ruben (orgs.). Os sentidos da integralidade na atenção e no cuidado à saúde. Rio de Janeiro: Uerj/IMS/ Abrasco, 2001. p. 113-126.

CENTRO DE PROMOÇÃO DA SAÚDE (CEDAPS). Construção compartilhada: mapeamento, 2009. Disponível em: <http://cedaps.org.br/>. Acesso em: 11 maio 2016.

ELIAS, Norbert; SCOTSON, John L. Os estabelecidos e os outsiders: sociologia das relações de poder a partir de uma pequena comunidade. Rio de Janeiro: Jorge Zahar Editor, 2000.

FORTES, Paulo A. C.; SPINETTI, Simone R. O agente comunitário de saúde e a privacidade das informações dos usuários. Cadernos de Saúde Pública, Rio de Janeiro, v. 20 n. 5, p. 1.328-1.333, set.-out. 2004.
FREIRE, Paulo. Ação cultural para a liberdade. 4. ed. Rio de Janeiro: Paz e Terra, 1979.

GOMES, Karine O. et al. A práxis do agente comunitário de saúde no contexto da Estratégia Saúde da Família: reflexões estratégicas. Saúde e Sociedade, São Paulo, v. 18, n. 4, p. 744-755, 2009.

HELMAN, Cecil G. Cultura, saúde e doença. Tradução Eliane Mussnich. 2 ed. Porto Alegre: Artes Médicas, 2009. p. 70-99.

LABONTE, Ronald. Estratégias para la promoción de la salud en la comunidad. In ORGANIZACIÓN PANAMERICANA DE LA SALUD (OPAS). Promoción de la salud: una antología. Washington: Opas, 1996. p. 153165. (Publicación científica, 557).

MERHY, Emerson E.; FRANCO, Túlio B. Trabalho em saúde. 2005. Disponível em: <http:// www.epsjv.fiocruz.br/upload/d/Trabalho_em_ Saude_ts.pdf $>$. Acesso em: 10 maio 2016.

MONKEN, Maurício; BARCELLOS, Christovam. O território na promoção e vigilância em saúde. In: FONSECA, Angélica F.; CORBO, Anamaria D. (orgs.). O território e o processo saúde-doença. Rio de Janeiro: EPSJV/Fiocruz, 2007. p. 177-224.

NORONHA, Maria G. R. C. S. et al. Resiliência: nova perspectiva na promoção da saúde da família? Ciência \& Saúde Coletiva, Rio de Janeiro, v. 14, n. 2, p. 497-506, mar.-abr. 2009.

NUNES, Mônica O. et al. O agente comunitário de saúde: construção da identidade desse personagem híbrido e polifônico. Cadernos de Saúde Pública, Rio de Janeiro, v. 8, n. 6, p. 1.639-1.646, nov.- dez. 2002.

PARREIRAS, Patrícia C.; MARTINS JR., Tomaz. A proposta político-pedagógica da Escola de Formação em Saúde da Família Visconde de Saboia. Sanare: Revista de Políticas Públicas, Sobral, v. 5, n. 1, jan.-mar. 2004. 
PEREIRA, Martha P. B.; BARCELLOS, Christovam. O território no programa de saúde da família. Hygeia: Revista Brasileira de Geografia Médica e da Saúde, Uberlândia, v. 2 n. 2, p. 47-55, jun. 2006.

QUEIRÓS, Arichele A. L.; LIMA, Luci P. A institucionalização do agente comunitário de saúde. Trabalho, Educação e Saúde, Rio de Janeiro, v. 10, n. 2, p. 257-281, jul.-out. 2012.

SEABRA, Daniela C.; CARVALHO, Antonio C. D.; FOSTER, Adaísa C. O agente comunitário de saúde na visão da equipe mínima de saúde. Revista de APS, Juiz de Fora, v. 11, n. 3, p. 226-234, jul.-set. 2008.

STARFIELD, Bárbara. Atenção primária: equilíbrio entre necessidades de saúde, serviços e tecnologia. Brasília: Unesco, Ministério da Saúde, 2002.
TOMAZ, José B. C. O agente de saúde não deve ser um 'super-herói'. Interface: Comunicação, Saúde, Educação, Botucatu, v. 6, n. 10, p. 84-87, fev. 2002.

TRAVASSOS, Cláudia; MARTINS, Mônica. Uma revisão sobre os conceitos de acesso e utilização de serviços de saúde. Cadernos de Saúde Pública, Rio de Janeiro, v. 20, supl. 2, p. s190-s198, 2004.

VIANA, Ana L.; DAL POZ, Mário R. A reforma do sistema de saúde no Brasil e o Programa de Saúde da Família. Physis: Revista de Saúde Coletiva, Rio de Janeiro, v. 15, supl., p. 225264, 2005. 